\title{
Representation of dynamical stimuli in threshold neuron models
}

\author{
Tatjana Tchumatchenko ${ }^{1,2,3^{*}}$, Theo Geisel ${ }^{1,2}$, Fred Wolf ${ }^{1,2,3}$ \\ From Twentieth Annual Computational Neuroscience Meeting: CNS*2011 \\ Stockholm, Sweden. 23-28 July 2011
}

A vital function of the mammalian cortex is the processing of dynamical stimuli. These stimuli are encoded in cortical neurons as modifications of the input current, which can be brief, prolonged or periodic, all depending on the type of the sensory stimulus, e.g. $[1,2]$. While experimental findings can increasingly link sensory stimulation to specific input current modulations, the representation of current stimuli by populations of cortical neurons currently lacks a comprehensive theoretical understanding. In particular, few theories can analytically describe the numerous phenomena related to the processing of dynamical current stimuli, such as pairwise spike correlations and spike triggered average currents (Fig. 1). Even in the simplest integrate and fire model, the complexity of the coupled differential equations allows for tractable analytical results only in specific limiting cases $[3,4]$. Here, we show how a modified threshold model framework can accurately describe many important features of cortical neurons and provide set of tractable analytical expressions for all quantities of

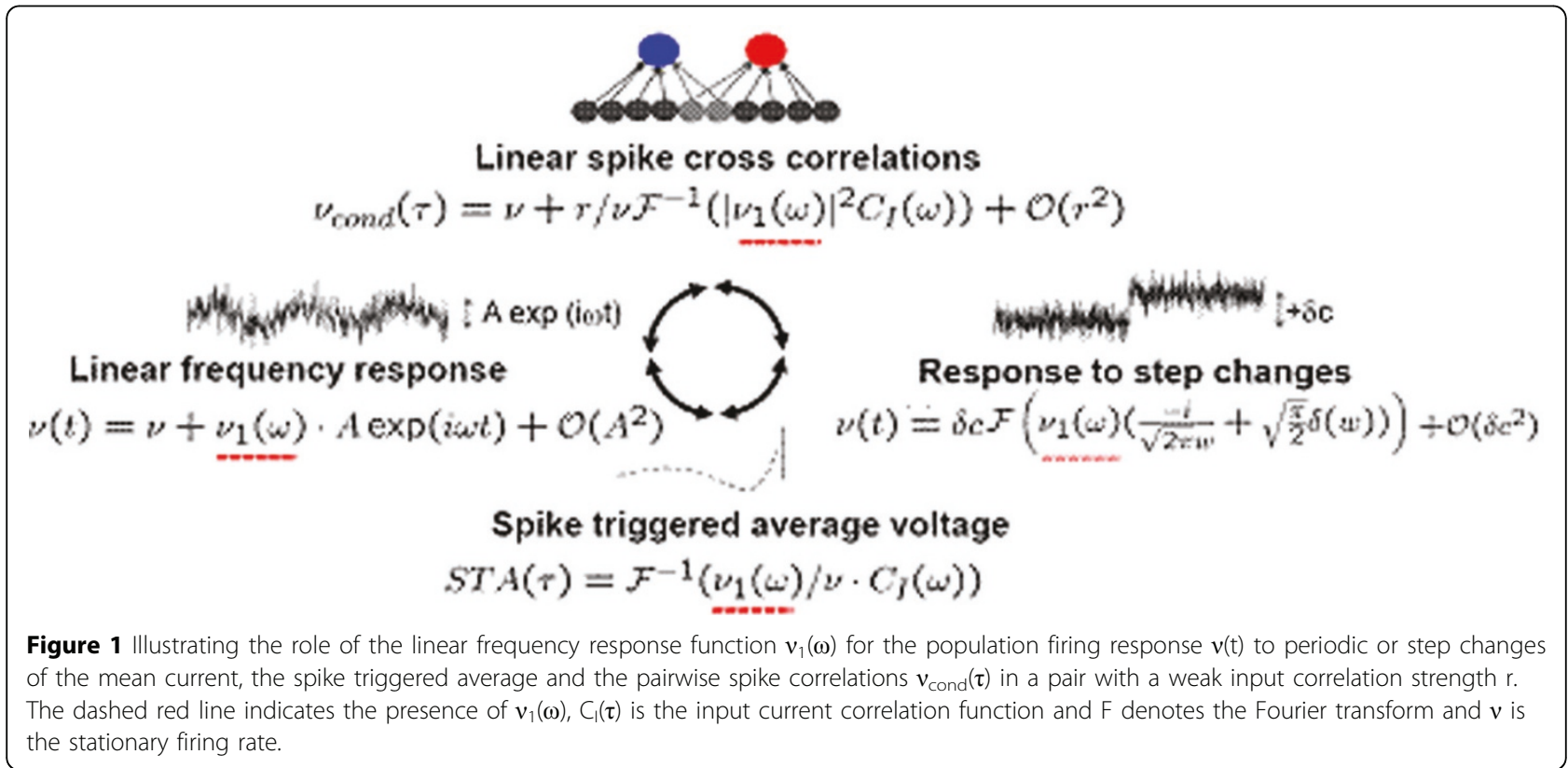

\footnotetext{
* Correspondence: tatjana@nld.ds.mpg.de

${ }^{1}$ Max Planck Institute for Dynamics and Self-Organization, 37073 Göttingen,

Germany

Full list of author information is available at the end of the article
}

\section{Biomed Central}

(c) 2011 Tchumatchenko et al; licensee BioMed Central Ltd. This is an open access article distributed under the terms of the Creative Commons Attribution License (http://creativecommons.org/licenses/by/2.0), which permits unrestricted use, distribution, and reproduction in any medium, provided the original work is properly cited. 
interest shown in Fig.1, such as spike triggered average current, pairwise spike correlations $[4,5]$ and response to dynamical input changes $[3,4]$. Using this novel model framework, we study how populations of cortical neurons represent dynamical stimuli encoded in the input current and place many important, yet disparate, observations into a common conceptual scheme.

\section{Acknowledgements}

We wish to thank Bundesministerium für Bildung und Forschung (\#01GQ0430,01GQ07113), German-Israeli Foundation (\#l-906-17.1/2006), Deutsche Forschungsgemeinschaft and Max Planck Society for financial support.

\section{Author details}

'Max Planck Institute for Dynamics and Self-Organization, 37073 Göttingen, Germany. ${ }^{2}$ Bernstein Center for Computational Neuroscience Göttingen, 37073 Göttingen, Germany. ${ }^{3}$ The interdisciplinary Collaborative Research Center 889 for Cellular Mechanisms of Sensory Processing, 37075 Göttingen, Germany.

Published: 18 July 2011

\section{References}

1. Buzsáki G, Draguhn A: Neuronal Oscillations in Cortical Networks. Science 2004, 304:1926-1929.

2. Volgushev M, Pernberg J, Eysel UT: $\gamma$-frequency fluctuations of the membrane potential and response selectivity in visual cortical neurons. Eur J Neurosci 2003, 17(9):1768-1776.

3. Brunel N, Chance F, Fourcaud N, Abbott LF: Effects of synaptic noise and filtering on the frequency response of spiking neurons. Phys Rev Lett 2001, 86:2186-2189.

4. Ostojic S, Brunel N, Hakim V: How connectivity, background activity, and synaptic properties shape the cross-correlation between spike trains. J Neurosci 2009, 29(33):10234-10253.

5. Tchumatchenko T, Malyshev A, Volgushev M, Wolf F: Correlations and synchrony in threshold neuron models. Phys Rev Lett 2010, 104(5):058102.

doi:10.1186/1471-2202-12-S1-P376

Cite this article as: Tchumatchenko et al.: Representation of dynamical stimuli in threshold neuron models. BMC Neuroscience 2011 12(Suppl 1): P376.

\section{Submit your next manuscript to BioMed Central and take full advantage of:}

- Convenient online submission

- Thorough peer review

- No space constraints or color figure charges

- Immediate publication on acceptance

- Inclusion in PubMed, CAS, Scopus and Google Scholar

- Research which is freely available for redistribution

Submit your manuscript at www.biomedcentral.com/submit
C Biomed Central 